University of Wollongong

Research Online

Faculty of Engineering and Information

Faculty of Engineering and Information

Sciences - Papers: Part A

Sciences

2013

Compare Pilot-Scale And Industry-Scale Models Of Pulverized Coal Combustion In An Ironmaking Blast Furnace

Yansong Shen

University of New South Wales

Aibing Yu

University of New South Wales

Paul Zulli

University of Wollongong, paulz@uow.edu.au

Follow this and additional works at: https://ro.uow.edu.au/eispapers

Part of the Engineering Commons, and the Science and Technology Studies Commons

Research Online is the open access institutional repository for the University of Wollongong. For further information contact the UOW Library: research-pubs@uow.edu.au 


\title{
Compare Pilot-Scale And Industry-Scale Models Of Pulverized Coal Combustion In An Ironmaking Blast Furnace
}

\author{
Abstract \\ In order to understand the complex phenomena of pulverized coal injection (PCI) process in blast furnace \\ (BF), mathematical models have been developed at different scales: pilot-scale model of coal combustion \\ and industry-scale model (in-furnace model) of coal/coke combustion in a real BF respectively. This paper \\ compares these $\mathrm{PCl}$ models in aspects of model developments and model capability. The model \\ development is discussed in terms of model formulation, their new features and geometry/regions \\ considered. The model capability is then discussed in terms of main findings followed by the model \\ evaluation on their advantages and limitations. It is indicated that these PCI models are all able to \\ describe $\mathrm{PCl}$ operation qualitatively. The in-furnace model is more reliable for simulating in-furnace \\ phenomena of $\mathrm{PCl}$ operation qualitatively and quantitatively. These models are useful for understanding \\ the flow-thermo-chemical behaviors and then optimizing the PCl operation in practice. 2013 AIP \\ Publishing LLC.
}

\section{Keywords}

pulverized, coal, combustion, ironmaking, blast, furnace, industry-scale, pilot-scale, compare, models

Disciplines

Engineering | Science and Technology Studies

\section{Publication Details}

Shen, Y., Yu, A. \& Zulli, P. (2013). Compare Pilot-Scale And Industry-Scale Models Of Pulverized Coal Combustion In An Ironmaking Blast Furnace. AIP Conference Proceedings, 1547 564-571. 


\title{
Compare Pilot-Scale And Industry-Scale Models Of Pulverized Coal Combustion In An Ironmaking Blast Furnace
}

\author{
Yansong Shen ${ }^{1}$, Aibing $\mathrm{Yu}^{1}$, Paul Zulli ${ }^{2}$ \\ 1: Laboratory for Simulation and Modelling of Particulate Systems, School of Materials Science and Engineering, \\ The University of New South Wales, Sydney, NSW 2052, Australia \\ 2: BlueScope Steel Research, P.O. Box 202, Port Kembla, NSW 2505, Australia
}

\begin{abstract}
In order to understand the complex phenomena of pulverized coal injection (PCI) process in blast furnace (BF), mathematical models have been developed at different scales: pilot-scale model of coal combustion and industry-scale model (in-furnace model) of coal/coke combustion in a real BF respectively. This paper compares these PCI models in aspects of model developments and model capability. The model development is discussed in terms of model formulation, their new features and geometry/regions considered. The model capability is then discussed in terms of main findings followed by the model evaluation on their advantages and limitations. It is indicated that these PCI models are all able to describe PCI operation qualitatively. The in-furnace model is more reliable for simulating in-furnace phenomena of PCI operation qualitatively and quantitatively. These models are useful for understanding the flow-thermo-chemical behaviors and then optimizing the PCI operation in practice.
\end{abstract}

Keywords: Multiphase Flow, Coal Combustion, Blast Furnace

\section{INTRODUCTION}

BF plays a dominant role in an integrated steel work in terms of energy consumption and $\mathrm{CO}_{2}$ emission [1-3]. PCI is one of the important recent technologies in BF ironmaking. It is widely used with various benefits, such as reducing coke consumption, adjusting furnace stability and reducing $\mathrm{CO}_{2}$ emission. As a result, the rate of PCI is increasingly high in practice [4-6]. Under the operation of high PCI rate, the injected coal cannot combust completely inside the raceway and therefore unburnt coal particles will affect the coke bed permeability and thereby the furnace operation (FIGURE. 1) [7]. Therefore, high coal burnout is desired and necessary for high PCI rate operation. In addition, proper gas composition and distribution are also needed for furnace stability in practice. Therefore, it is important to understand the in-furnace phenomena associated with PCI operation under various operational conditions for providing direct guidance to optimize the operating conditions, aiming to improve the coal burnout and adjust gas distribution in practice.

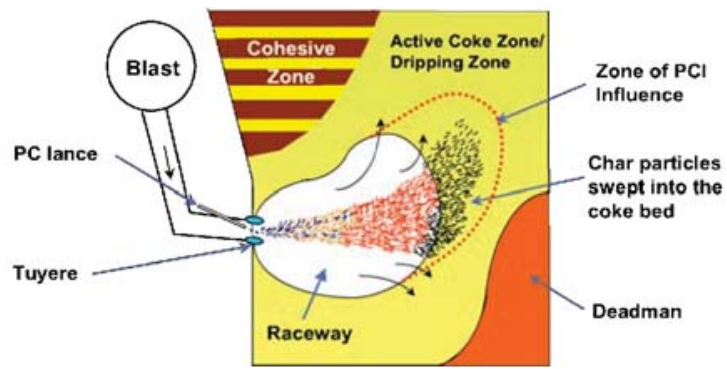

FIGURE. 1. Schematic of pulverized coal injection in the lower part of a BF.

This technology has been studied using different techniques. Industrial-scale studies of these in-furnace phenomena are extremely difficult due to the hazardous in-furnace environment. Laboratory- and pilot- scales experimental studies are difficult to replicate the comprehensive in-furnace conditions of the raceway-coke bed region, and also very expensive in terms of time and investment. Mathematical modelling provides a cost-effective way of understanding PCI operation. In the past, several PCI models were reported in the literature. In the 1990s, several PCI models in twodimension were developed. They can simulate some phenomena related to PCI process. For example, Takeda and Lockwood [8] reported a model of coal combustion using two computational domains of raceway and coke bed. Threedimensional (3D) modelling is needed for more practical problems. Recently, several 3D PCI models were developed. For example, Goto et al. [9] reported a 3D simulation for blowpipe region and on this basis some lance arrangements were examined for co-injections of coal/plastic and coal/gas. The region of tuyere and raceway was not included in the simulations. Nogami et al. [10] reported a 3D transient-state model for a laboratory-scale test rig. The so-called discrete 7th International Symposium on Multiphase Flow, Heat Mass Transfer and Energy Conversion AIP Conf. Proc. 1547, 564-571 (2013); doi: 10.1063/1.4816909

(C) 2013 AIP Publishing LLC 978-0-7354-1172-2/\$30.00 
element method was used for coke movement so that the raceway structure could be directly predicted. But this approach is generally difficult to apply to a practical system where the number of coke particles is huge, and thus the computation will be extremely expensive. To solve these deficiencies, several 3D CFD models have been developed and conducted for PCI operation at different scales: coal combustion in a pilot-scale test rig of raceway region and an in-furnace phenomena model considering coal/coke combustion in the region of tuyere-raceway-coke bed in a real $\mathrm{BF}$ [11-18].

In this paper, these PCI models are compared in terms of model development and their applicability. The model development is compared in terms of model formulations, new features and geometry applied. The model applicability is compared about the main findings, such as flow, temperature, gas composition, and coal burning characteristics. Based on these comparisons, the functionalities and limits of these models are evaluated.

\section{MODEL DEVELOPMENTS}

Aiming to simulate the complicated phenomena of PCI operation in the lower part of BF, various models are developed in different scales for different purposes. Specifically, they are: pilot model of pulverized coal combustion in a test rig and in-furnace model of coal/coke combustion in a real BF). In this session, the model framework about general model formulation is described firstly. Then the model developments of the PCI models are compared in terms of geometry, new model features, region considered and main purposes.

The general model framework shared by the two models is briefly outlined below. The gas-solid flow is assumed to be steady state. The gas phase is treated with an Eulerian frame of reference and described by a set of 3D, steady-state Navier-Stokes equations, closed by the standard $k-\varepsilon$ turbulence model equations. They are solved for pressure $(p)$, velocity $(u, v, w)$, turbulence kinetic energy $(k)$, turbulence dissipation rate $(\varepsilon)$, enthalpy $(H)$, and several gas species mass fractions $\left(Y_{i}\right)$. The particle phase is modeled in a Lagrangian frame of reference, where the trajectories of the discrete particles are determined by integrating Newton's second law of motion. The drag force and turbulence dispersion are included. The change of particle temperature is governed by three physical processes: convective heat transfer, latent heat transfer associated with mass transfer, and radiative heat transfer. Coal combustion is regarded as a multi-stage process: 1) preheating; 2) devolatilization of raw coal, modeled using the two-competing model [19]; 3) gaseous combustion, modeled using the eddy dissipation model [20]; 4) the oxidation and gasification of residual char, modeled using the Gibb model [21]. The governing equations for the gas and particle phases and the reactions of coal and their reaction rate expressions are reported elsewhere [17]. The models are developed based on the framework of software package ANSYS-CFX [21].

Although the above general model formulation, these PCI models also include different features, in terms of geometry applied and fuels considered etc.

\section{Pilot-scale model (tuyere-raceway region in a test rig)}

Aiming to overcome the deficiencies of previous coal combustion models of PCI operation in one-, two-, and threedimension, this 3D model has been developed for simulating pulverized coal combustion [11, 12]. As a start-up of comprehensive modelling of PCI process, this model is developed to simulate the flow and combustion behaviors of pulverized coal in a pilot-scale test rig, as shown in FIGURE 2-3. This modelling region includes the tuyere and raceway centreline (i.e. along main coal plume), according to the test rig configuration (dashed zone). The main purpose of this model is for model validation and fundamental analysis of combustion behaviors of pulverized coal. The model is validated against the experimental data collected from two different test rigs obtained by Mathieson et al [7] and Rogers [22], in terms of both coal burnout and gas composition: 1) The model is found acceptable for burnout predictions, not only at one specific position (i.e. port 5 at $925 \mathrm{~mm}$ in FIGURE 2) but also for the whole evolution along the main coal plume, i.e., not only near the end of raceway but also near the tuyere [11]. Moreover, 2) it is acceptable for not only single coal [11] but also coal blends [13]. 2) The model can also produce the evolutions for major gas species, compared to the previous 3D models [23].

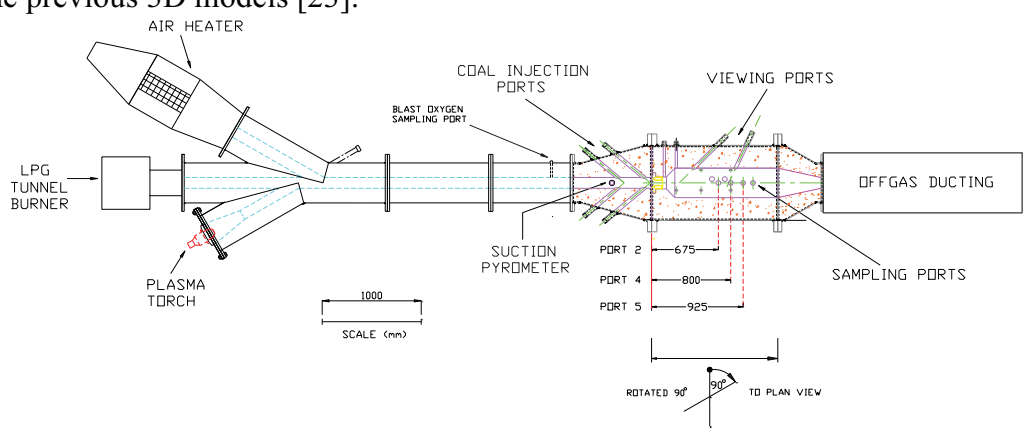

FIGURE 2. Schematic of the pulverised coal combustion test rig in BHP Newcastle Laboratories [7]. 


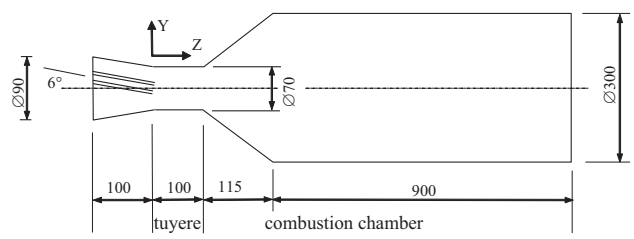

FIGURE 3. Geometry details of the pilot model (in mm).

\section{In-furnace model (blowpipe-lance-tuyere-raceway-coke bed in a BF)}

Standing as a comprehensive model of PCI process, this in-furnace model is developed based on the pilot model, i.e. from one fuel (pulverized coal only in cavity) to two fuels (both pulverized coal and coke in cavity/packed bed). That is, this model is developed to describe the flow and combustion behaviors of both pulverized coal and coke under practical conditions (FIGURE 4). This modelling region includes the blowpipe, lance, tuyere, raceway centreline/recirculation, and coke bed, using one single computational domain. It is noted that the raceway is treated as a $3 \mathrm{D}$ balloon-shape cavity (FIGURE 4(a)), so that more reliable information can be obtained, i.e. not only along the main coal plume but also additional information over the raceway surface. The main purpose of this model is to describe the in-furnace phenomena of PCI operation in a real BF. Moreover, it is also used to investigate the role of raceway recirculation region in PCI simulations. In addition to model formulation described in the pilot model, the in-furnace model also includes the raceway recirculation, and coke bed and its reactions. One computational area covers the lance, blowpipe, tuyere, raceway, and coke bed, so that the in-furnace phenomena of PCI operation can be studied under various conditions. The blowpipe-tuyere-raceway region is treated as a cavity. The coke bed is treated as a porous media, where the momentum source through the coke packed bed is obtained by Ergun equation. The Field model [24] is used for coke reactions in the coke bed, including coke solution loss and coke combustion. In addition to the validation in terms of coal burnout mentioned above, the model is also validated against measurements in different scales, from laboratory scale to industry scale, such as several basic variables (gas velocity, temperature and concentration) from a laboratory scale experiment [25]; and more importantly in terms of gas composition from a real BF (No. 4 blast furnace of Newcastle in Australia) [26], respectively.
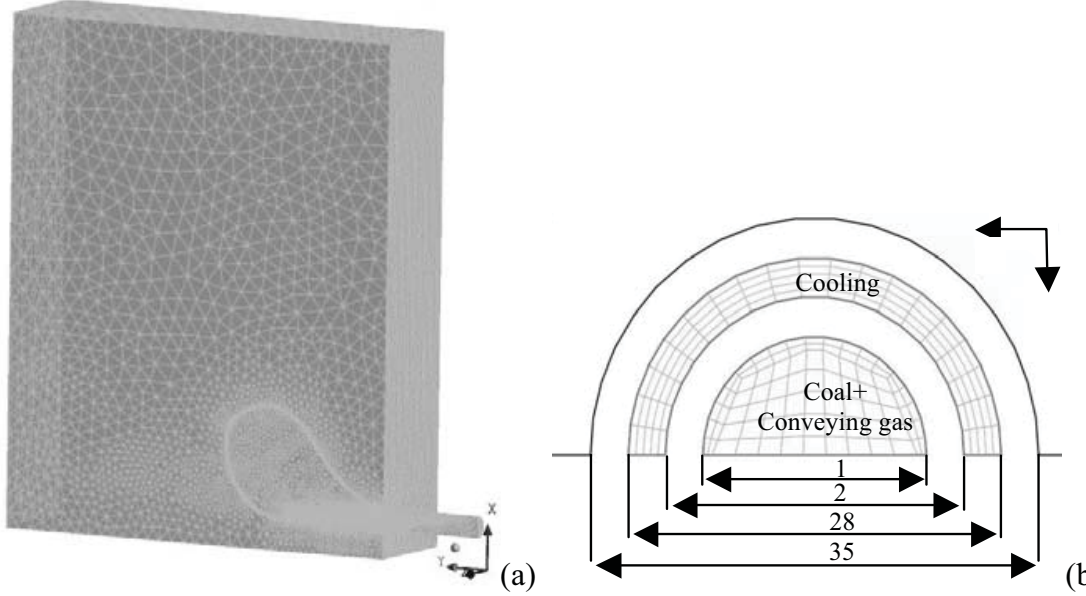

(b)

FIGURE 4. Geometry details of industry-scale model: (a), the whole model; and (b), lance tip details (in mm).

\section{MODEL APPLICATIONS}

In the following session, the typical results of PCI operation in aspects of flow and associated thermal-chemical behaviors simulated by the two models will be compared in terms of the applicability and functionality, so as to establish a clear picture of in-furnace phenomena about PCI operation in BF step by step and then identify some important issues, e.g. which model is preferred for fundamental study; which model is preferred for practice analysis; and the role of inclusion of raceway recirculation region in PCI simulations.

\section{Pilot model (tuyere-raceway region in a test rig)}

Using this model, the typical transport phenomena of flow and combustion in a pilot-scale PCI test rig are simulated and analyzed under test rig conditions, such as temperature field, oxygen distribution and coal burnout (FIGURE 5). The main results indicate that: 1) the main coal plume shows higher velocity, higher temperature, and lower burnout, compared with the peripheral region, where fine coal particles recirculate; 2) the burnout level of coal along the central plume is determined by combined contributions from both devolatilization upstream and char oxidation/gasification downstream. In terms of increasing coal burnout, the contribution of volatile release/combustion is more significant than the reactions of char. In addition, the role of two additional gasification reactions in determining coal burnout and 
gas composition is examined. Compared to a previous 3D model [23], it is indicated the inclusion of two additional gasification reactions (i.e., solution loss and water gas of char) makes a significant difference to burnout evolution and thus should not be neglected in future PCI modelling [11].
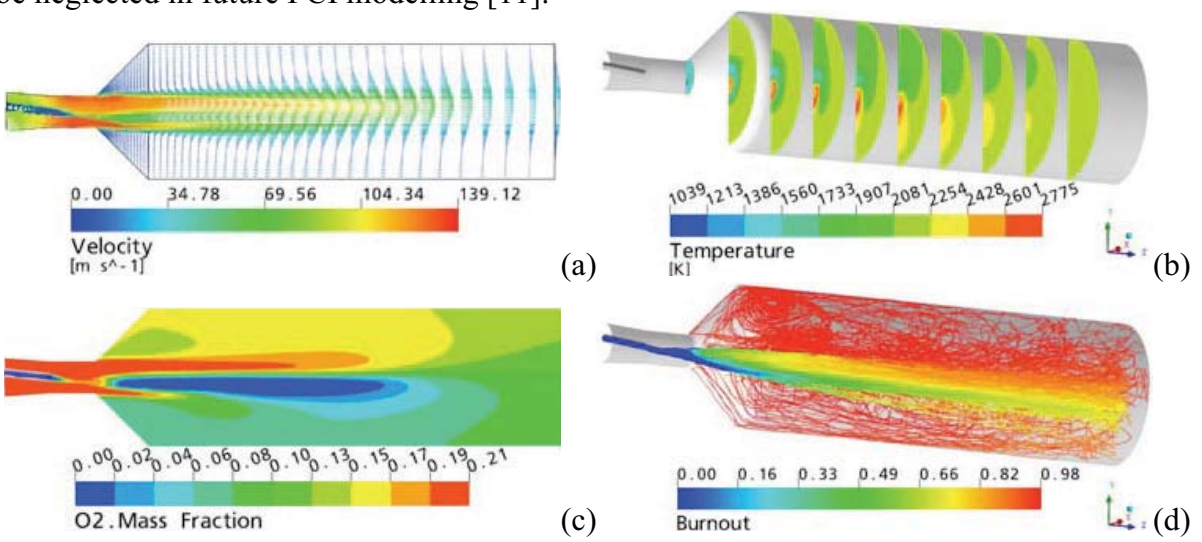

FIGURE 5. Main simulation results using the pilot model: (a), gas flow; (b), temperature; (c), oxygen distribution; and (d), coal burnout along particle trajectories.

Then a parametric study of operational conditions is conducted to examine effects of coal properties and blast conditions on coal burnout evolution along tuyere axis. The results confirm that notable improvements in final burnout can be achieved for coals with more fine particles and high volatile matter, and by higher oxygen enrichment. Some quantitative relationships between burnout and these variables have been formulated based on the numerical results. In addition, the insights of some experimental observations with little explanations can be explored, for example, blast temperature. The use of high blast temperature can increase coal burnout, but the further increase in blast temperature over $1200^{\circ} \mathrm{C}$ has little effect on final burnout. This is different from the noted impact of blast temperature reported in the previous simulations considering tuyere only. It is explained that as the blast temperature increases over $1200^{\circ} \mathrm{C}$, the devolatilization processes may not complete in the tuyere but have already been completed within a very short distance in the raceway.

\section{In-furnace model (blowpipe-lance-tuyere-raceway-coke bed in a BF)}

In the in-furnace model, both pulverized coal and coke are considered in the regions of not only blowpipe, tuyere, raceway centreline, but also raceway recirculation and the surrounding coke bed. Based on this model, the comprehensive in-furnace phenomena are investigated in the raceway and coke bed, in terms of flow, temperature, gas composition, and coal burning characteristics (FIGURE 6). It is indicated that: (1) Inside the raceway: main coal plume and recirculation region show different patterns. Compared to the recirculation region, the main coal plume shows considerably higher gas velocity, shorter particle residence time, higher gas temperature and significantly higher $\mathrm{CO}_{2}$ and VM concentrations. The coal is heated and does not start burning until exiting the tuyere; subsequently the burnout increases rapidly at the upstream of the raceway due to strong devolatilization and then plateaus at the downstream of the raceway due to slow char reactions. (2) In the coke bed: compared with the dripping zone, the deadman shows slightly lower gas velocity and longer residence time with large particle size, significantly higher $\mathrm{CO}$, lower $\mathrm{O}_{2}$ concentrations, and a lower burnout. (3) Local coal burnout mainly depends on particle size, residence time and oxygen availability in both the raceway and coke bed.
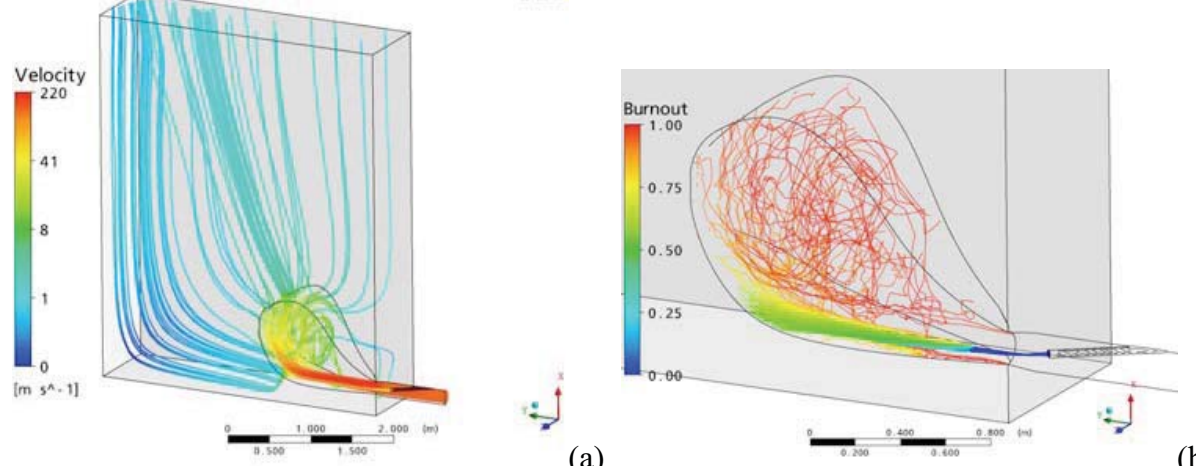

(a) 


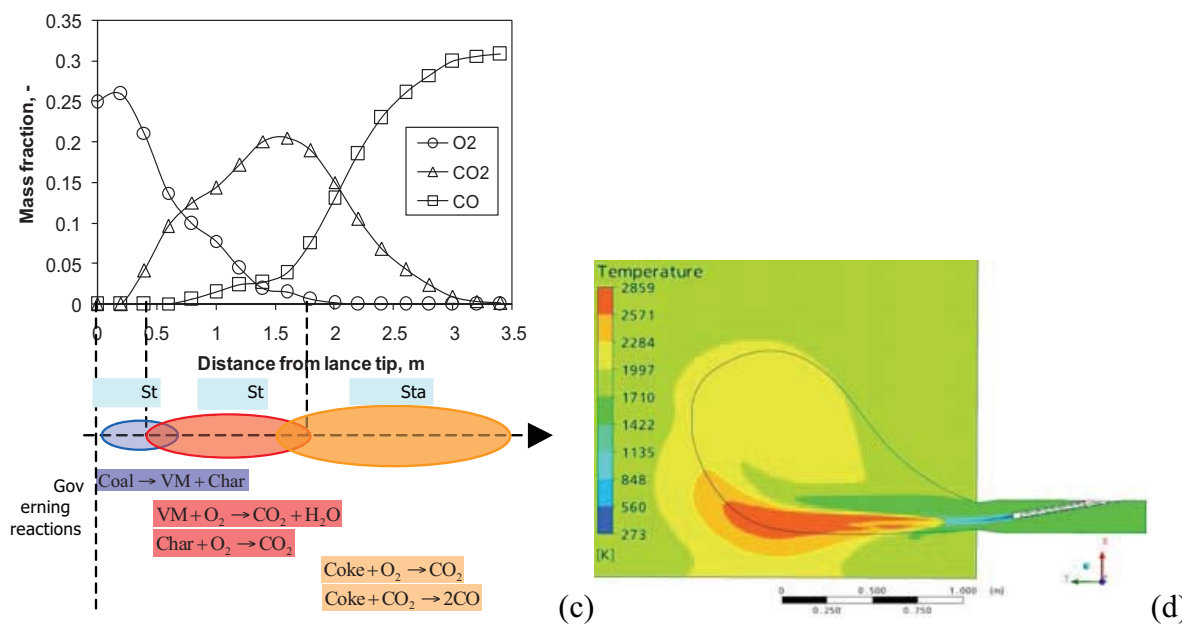

FIGURE 6. Main simulation results using the in-furnace model: (a), gas flow; (b), coal burnout in the raceway; (c), gas composition along the tuyere axis; and (d), temperature field in the raceway and surrounding coke bed.

The in-furnace model includes more complex settings, such as recirculation region of raceway, surrounding coke bed and its reactions etc, and thus is regarded as a more robust and reliable model for describing in-furnace phenomena of PCI process. When comparing the simulations using in-furnace model with those using pilot model under the same conditions, (a), in this study along the main coal plume, the dispersion of the coal plume is limited within the tuyere but more significant in the raceway. Then a large-scale recirculation of fine coal particles forms in the upper part of raceway, thus having a longer residence time; (b), the in-furnace model predicts a lower temperature in the raceway; (c), the previous models were found to greatly under-predict the $\mathrm{CO}$ concentration in the raceway; and (d), the in-furnace model predicts a lower final burnout along the tuyere axis by $\sim 9 \%$ (absolute) due to the fact that fine particles of higher burnout have left the main coal plume before reaching the end of raceway. The inclusion of recirculation region of raceway and the surrounding coke bed plays an important role in determining burnout. These comparisons also indicate that it is important to include recirculation region in the future numerical studies of PCI operation for better understanding in-furnace phenomena. More importantly, compared with final burnout at one point predicted in previous models, this model could give a more reliable burnout prediction over the raceway surface, which could better represent the amount of unburnt char entering the coke bed. The average burnout over the raceway surface is usually much higher than the burnout in the end of raceway, but much more sensitive to the change of variables [16, 18]. This is not achievable by the previous PCI models.

To sum up, in order to describe the PCI operation comprehensively, the two models in different scales have been developed for different purposes. They are summarized as detailed in TABLE 1 in terms of model developments and capability, such as purpose, fuel considered, simulation scales, regions considered, burnout calculations etc.

TABLE 1. Model comparisons in terms of model developments and capability.

\begin{tabular}{|c|c|c|}
\hline & Pilot model & In-furnace model \\
\hline Purpose & Model validation $\&$ fundamental analysis & In-furnace phenomena understanding \\
\hline Fuel considered & Coal & Coal \& coke \\
\hline Simulation scale & Pilot-scale experiments & Full-scale BF \\
\hline Region covered & Tuyere-raceway axis & Lance-blowpipe-tuyere-raceway- coke bed \\
\hline Raceway recirculation & Not considered & Yes considered \\
\hline Burnout calculations & Along tuyere axis only & Along tuyere axis \& over raceway surface \\
\hline Burnout at raceway end point & $72 \%{ }^{*}$ & $57 \%$ \\
\hline Burnout over the raceway surface & 1 & $90 \%$ \\
\hline Major gas products & $\mathrm{CO}_{2}$ & $\mathrm{CO}$ \\
\hline Residence time of coal ${ }^{\dagger}$ & $0.05 \mathrm{~s}$ & $0.6 \mathrm{~s}$ \\
\hline
\end{tabular}

* Note that this burnout is obtained under the test rig conditions and thus not eligible for comparing with those under BF conditions.

${ }^{\dagger}$ Residence time of coal for pilot model represents coal travelling time along the tuyere axis; residence time of coal for in-furnace model represents coal travelling time along the tuyere axis and then along the recirculation in the raceway.

On the other hand, based on the comparisons in terms of model developments and capability, the two models are evaluated in terms of advantages and limitations, as below:

Pilot model: Such simulations under test rig conditions can help analyze the fundamental combustion behaviors associated with PCI operation to a certain degree but mainly for validation purposes. It is also useful to examine basic combustion variables in aspects of qualitative analysis. On the other hand, a too confined set-up for physical or numerical experimentation may not be able to generate a full picture regarding this process. It is suggested that it is 
necessary to consider the real BF conditions, in terms of boundary conditions and geometry e.g. raceway recirculation region, when investigating the effects of variables on coal burnout. These two aspects are solved by the in-furnace model.

In-furnace model: The deficiencies of the previous models, including the pilot model, can be overcome by the infurnace model. This model is the first 3D model to simulate the in-furnace phenomena of PCI operation in the literature. This model provides a cost-effective tool for comprehensively understanding the in-furnace flow-thermo-chemical behaviors of the PCI operation, and then optimizing operating conditions in full-scale BFs in the future.

\section{CONCLUSIONS}

This paper briefly reviews and compares two PCI models at different scales. They are pilot model of pulverized coal combustion in a pilot-scale test rig and in-furnace model of coal/coke combustion in a real BF. These models are compared in aspects of model developments, such as geometry and the regions considered, and then model applicability, such as flow, temperature, gas composition, and coal burning characteristics. It is indicated that both two PCI models are able to describe PCI operation qualitatively. The in-furnace model is more reliable for simulating in-furnace phenomena of PCI operation qualitatively and quantitatively. Such model gives a more reliable burnout prediction over the raceway surface, which could better represent the amount of unburnt char entering the coke bed and is found more sensitive to the change of operational conditions. Then based on these comparisons, they are evaluated on advantages and limitations. It is indicated that pilot model is suitable for fundamental studies; in-furnace model includes more complex conditions/settings such as recirculation region of raceway, surrounding coke bed and its reactions etc, and thus is regarded as a more robust and reliable model for describing in-furnace phenomena of PCI process. These models are useful for understanding the flow-thermo-chemical behaviors and then optimizing the PCI operation in BFs.

\section{NOMENCLATURE}

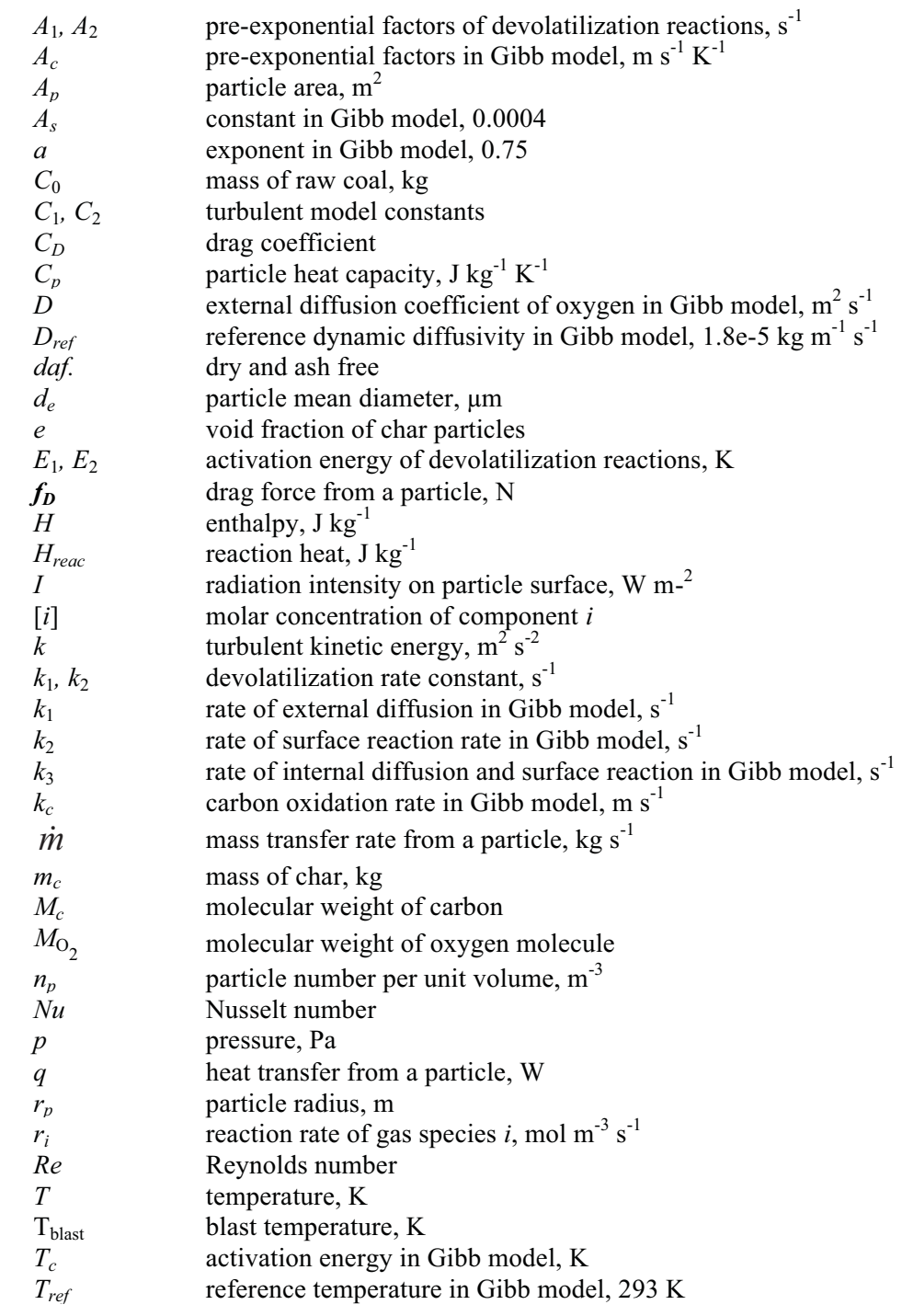




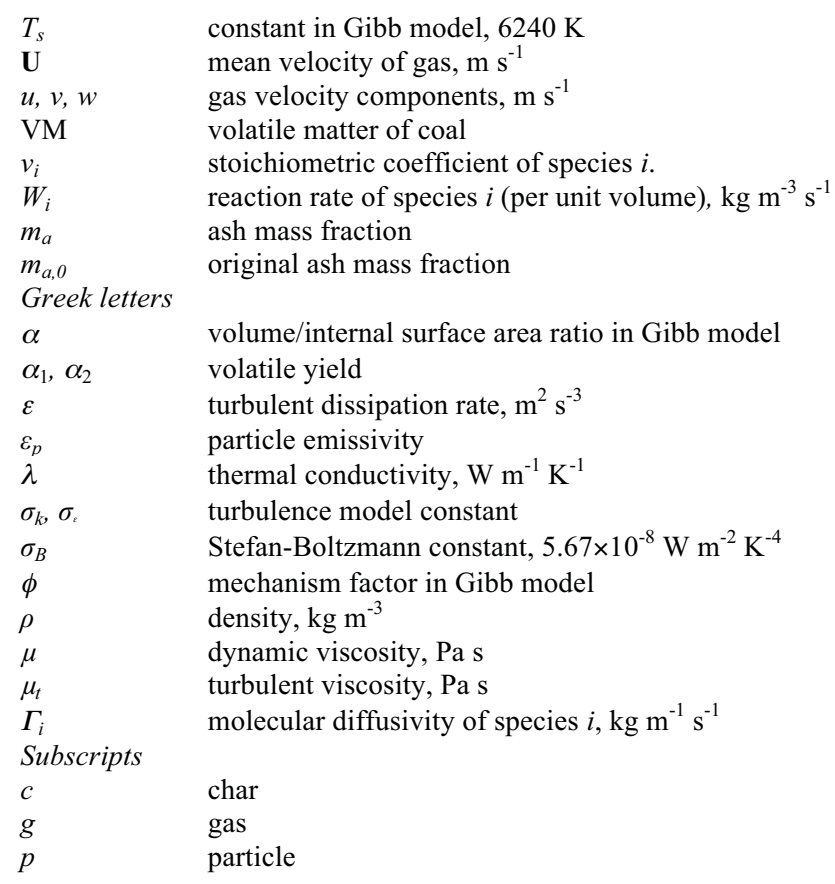

\section{ACKNOWLEDGEMENTS}

We wish to thank the Australian Research Council and BlueScope Steel for their support of this project.

\section{REFERENCES}

1. Ishii, K., Advanced pulverised coal injection technology and blast furnace operation. 2000, Oxford, UK: Elsevier.

2. Yu, A.B. and Y.S. Shen, Editorial Introduction - The 3rd Australia-China-Japan Joint Symposium on Iron and Steelmaking. Steel Research International, 2011. 82(5): p. 465-465.

3. Shen, F.M., et al., Proper MgO addition in blast furnace operation. ISIJ International, 2006. 46(1): p. 65-69.

4. Shen, F.M., et al., Industrial practice of BiPCI process of pulverized coal injection for blast furnace ironmaking at SSAB. Steel Research International, 2008. 79(1): p. 11-16.

5. Shen, F.M., et al., An industrial investigation of Bi-PCI process in a blast furnace. Journal of Iron and Steel Research International, 2009. 16: p. 753-757.

6. Shen, Y.S., et al., Modelling in-furnace phenomena of pulverized coal injection in ironmaking blast furnace: Effect of coke bed porosities. Minerals Engineering, 2012. 33(0): p. 54-65.

7. Mathieson, J.G., J.S. Truelove, and H. Rogers, Toward an understanding of coal combustion in blast furnace tuyere injection. Fuel, 2005. 84(10): p. 1229-1237.

8. Takeda, K. and F.C. Lockwood, Integrated mathematical model of pulverised coal combustion in a blast furnace. ISIJ International, 1997. 37(5): p. 432-440.

9. Goto, K., et al. Massive combustion technology of solid fuel injected into blast furnace. in International Blast Furnace Lower Zone Symposium. 2002. Wollongong, Australia: Australasian Institute of Mining and Metallurgy (AusIMM).

10. Nogami, H., H. Yamaoka, and K. Takatani, Raceway design for the innovative blast furnace. ISIJ International, 2004. 44(12): p. 2150-2158.

11. Shen, Y.S., et al., Three-dimensional modelling of coal combustion in blast furnace. ISIJ International, 2008. 48(6): p. 777-786.

12. Shen, Y.S., et al., Model study of the effects of coal properties and blast conditions on pulverized coal combustion. ISIJ International, 2009. 49(6): p. 819-826.

13. Shen, Y.S., et al., A three-dimensional numerical study of the combustion of coal blends in blast furnace. Fuel, 2009. 88 (2): p. 255-263.

14. Shen, Y.S., et al., Computational fluid dynamics study of pulverized coal combustion in blast furnace raceway. Industrial \& Engineering Chemistry Research, 2009. 48(23): p. 10314-10323.

15. Shen, Y.S., et al., An Integrated Model of Coal/Coke Combustion in a Blast Furnace, in AIP Conference Proceedings 1207 (6th International Symposium on Multiphase Flow, Heat Mass Transfer and Energy Conversion), L.J. Guo, et al., Editors. 2010, Amer Inst Physics: Melville. p. 822-828.

16. Shen, Y.S., et al., Modelling in-furnace phenomena of coal/coke combustion in a blast furnace: effects of coal 
properties. Journal of Iron and Steel Research International, 2009. 16: p. 1137-1142.

17. Shen, Y.S., et al., Three-dimensional modelling of in-furnace coal/coke combustion in a blast furnace. Fuel, 2011. 90(2): p. 728-738.

18. Shen, Y.S., et al., CFD study of in-furnace phenomena of pulverised coal injection in blast furnace: Effects of operating conditions. Powder Technology, 2012. 223(0): p. 27-38.

19. Ubhayakar, S.K., et al. Rapid devolatilization of pulverized coal in hot combustion gases. in 16th Symposium (International) on Combustion. 1976. Pittsburgh: The Combustion Institute.

20. Magnussen, B.F. and B.W. Hjertager. On mathematical modelling of turbulent combustion with special emphasis on soot formation and combustion. in 16th Symposium (International) on Combustion. 1977. Pittsburgh: The Combustion Institute.

21. ANSYS-CFX-Documentation.

22. Rogers, H., PCI combustion tests, in Internal BlueScope Steel Report 2004.

23. Guo, B.Y., et al., Three-dimensional simulation of flow and combustion for pulverised coal injection. ISIJ International, 2005. 45(9): p. 1272-1281.

24. Field, M., et al., The combustion of pulverised coal. 1967, London: British Coal Utilisation Research Association.

25. Truelove, J.S. and D. Holcombe, Measurement and modelling of coal flame stability in a pilot-scale combustor. Symposium (International) on Combustion, 1991. 23(1): p. 963-971.

26. Jamaluddin, A.S., Combustion of pulverised coal as a tuyere-injectant to blast furnace, 1985, University of Newcastle: Newcastle. 
Copyright of AIP Conference Proceedings is the property of American Institute of Physics and its content may not be copied or emailed to multiple sites or posted to a listserv without the copyright holder's express written permission. However, users may print, download, or email articles for individual use. 